\title{
A SIMPLE METHOD TO SEPARATE POLLEN FOR AMS RADIOCARBON DATING AND ITS APPLICATION TO LACUSTRINE AND MARINE SEDIMENTS
}

\author{
Scott A Mensing \\ Department of Geography, University of Nevada, Reno, Nevada 89507 USA
}

\section{John R Southon}

Center for Accelerator Mass Spectrometry, Lawrence Livermore National Laboratory, Livermore, California 94551 USA

\begin{abstract}
We present a simple method for manually separating pollen concentrates for radiocarbon accelerator mass spectrometry (AMS) dating using a mouth pipetting system. The required equipment is readily available from scientific equipment supply houses at minimal cost. Pollen samples from lake sediments required about $4 \mathrm{~h}$ of hand picking, whereas samples from marine sediments required about $8 \mathrm{~h}$ labor. Pollen dates from marine sediments were much older than expected. We are attempting to resolve whether this is due to contamination of the pollen or the presence of significant quantities of old reworked pollen. Pollen dates from lake sediments associated with Mazama Ash were consistent with other published ages; however, replicate dates on pollen samples from above the ash were consistently older than the surrounding sediment. Our results suggest that caution must be used when interpreting pollen dates if the potential for sediment reworking is present.
\end{abstract}

\section{INTRODUCTION}

The ability to obtain reliable radiocarbon dates from pollen using accelerator mass spectrometry (AMS) is well established (Brown et al. 1989, 1992). A number of methods have been developed to concentrate pollen samples for AMS ${ }^{14} \mathrm{C}$ analysis. In the first published work on the topic, Brown et al. (1989) obtained pollen concentrates from lake sediments using a variation of the standard palynological pretreatment of samples (Faegri and Iversen 1975) followed by repeated bleaching and sieving. Brown et al. (1989) dated bulk sediments and pollen concentrates from samples associated with previously dated horizons, including the Mazama Ash. Pollen dates were younger than bulk sediment dates, but were consistent with the range of commonly cited dates for the Mazama Ash. In a later paper, Brown et al. (1992) tested a set of modified preparation procedures on 6 samples from peat deposits associated with the Mazama Ash. The procedures were sufficient to remove nearly all non-pollen materials and the dates again were consistent with other published dates for the Mazama Ash.

Efforts to concentrate pure pollen samples from sites in other regions have generally found that the procedures developed by Brown et al. (1989) did not remove sufficient organic materials to produce a datable sample (Long et al. 1992; Regnell 1992). New methods have been developed to improve the removal of chemically resistant organic matter from peats (Richardson and Hall 1994) and hard-water lakes (Long et al. 1992; Regnell 1992). These methods include the use of strong acids such as $\mathrm{H}_{2} \mathrm{SO}_{4}$ (Regnell 1992), microbiological degradation (Richardson and Hall 1994), centrifugation (Regnell and Everitt 1996), and manual separation with a micromanipulator (Long et al. 1992). Although each of these new procedures has resulted in some improvements, they typically required purchase of expensive specialized equipment and materials (Long et al. 1992; Regnell and Everitt 1996), or were not able to completely remove contaminants (Regnell 1992; Richardson and Hall 1994).

We have developed a simple, inexpensive method for manually separating pollen from detrital material for AMS dating. We have tested our procedures on lake sediments associated with Mazama Ash from the Sierra Nevada, California, and on varved marine sediments of known age from the Santa Barbara Basin, California. 


\section{METHODS}

Lake sediment samples used in this study were from a 2-cm Livingstone core recovered from Lake Moran, California, USA $\left(38^{\circ} 23^{\prime} 00^{\prime \prime} \mathrm{N}, 120^{\circ} 07^{\prime} 45^{\prime \prime} \mathrm{W}\right.$, elev. $\left.2006 \mathrm{~m}\right)$, by Roger Byrne and Eric Edlund, University of California, Berkeley. The lake lies in a granitic basin dammed by a terminal moraine on the western slope of the Sierra Nevada. Mazama Ash is present as a 3-cm thick layer at a depth of 229-232 cm and has been identified as the Tsoyawata Ash bed (Llao Rock event) that was a precursor to the climactic Mazama eruption (Byrne, personal communication). At Osgood Swamp $\left(38^{\circ} 50^{\prime} 45^{\prime \prime} \mathrm{N}, 120^{\circ} 02^{\prime} 30^{\prime \prime} \mathrm{W}\right)$, about $50 \mathrm{~km}$ northeast of Lake Moran near the crest of the Sierra Nevada, tephra was also identified as the Tsoyawata Ash (Davis 1978; Bacon 1983; Hallett et al. 1997). In this region, the climactic Mazama Ash bed has been found only at sites east of the Sierra Nevada (Davis 1978). The climactic Mazama Ash and the Tsoyawata Ash have been found together at several localities in the Lahontan Basin (Davis 1978) and in Mono Lake (Davis forthcoming).

One-cm thick samples were obtained from immediately above and below the ash. The annual pollen accumulation rate for Lake Moran exceeds 50,000 grains $\mathrm{cm}^{-2} \mathrm{yr}^{-1}$, with pine representing 50\% of the pollen sum; consequently only a small sample (3-5 g wet weight) was processed.

Marine sediments were obtained from box cores recovered from the Santa Barbara Basin, California, USA $\left(34^{\circ} 15^{\prime} \mathrm{N}, 119^{\circ} 52^{\prime} \mathrm{W}\right)$, by Tim Baumgartner, Scripps Institute for Oceanography. Anoxic conditions in the basin support virtually no benthic life and support the preservation of annually laminated varves. Varve thickness averages $2.0 \mathrm{~mm}$ per pair of laminae (Hulsemann and Emery 1961), or $5 \mathrm{yr}$ per centimeter, a rapid sedimentation rate that allows for high-resolution sampling. The annual nature of the Santa Barbara sediments has been confirmed by ${ }^{14} \mathrm{C}$ age determination (Emery 1960), ${ }^{210} \mathrm{~Pb}$ measurements (Koide, Soutar and Goldberg 1972; Krishnaswami et al. 1973; Bruland 1974), correlation with precipitation records and tree-ring indices (Soutar and Crill 1977), and through correlation with fluctuations in microfossil assemblages associated with strong El Niño events (Schimmelmann et al. 1990). Average annual pollen accumulation rate in the Santa Barbara Basin is only 3500 grains $\mathrm{cm}^{-2} \mathrm{yr}^{-1}$, (Mensing 1993), and pine represents only $10 \%$ of the pollen sum; therefore, relatively large samples (45-65 g wet weight) were required for processing. Three consecutive 5-yr sediment samples from 1963-1977 and 4 additional 10-30-yr samples from 18601950 were treated for pollen extraction.

Pollen extraction generally followed Brown et al. (1989). Carbonates were removed with $10 \% \mathrm{HCl}$. Sediments were then boiled in $\mathrm{KOH}$ for $20 \mathrm{~min}$ to remove humic acids. Silicates were digested with $49 \% \mathrm{HF}$ in a hot bath for a minimum of $1 \mathrm{~h}$, followed by $10 \% \mathrm{HCl}$ in a boiling bath for $10 \mathrm{~min}$. Following treatment with $2 \%-3 \% \mathrm{NaOCl}$, samples were sieved with $38 \mu \mathrm{m}$ and $74 \mu \mathrm{m}$ mesh to concentrate pine pollen, the largest common pollen type in our study areas. The $>74 \mu \mathrm{m}$ and $<38 \mu \mathrm{m}$ fractions were decanted into vials for dating. Visual analysis of both size fractions revealed that they contained primarily non-pollen material. The $38-74 \mu \mathrm{m}$ fraction was then treated with $\mathrm{NaOCl}$ twice more, followed by sieving after each treatment. The 2 nd and $3 \mathrm{rd}$ bleach/sieve treatments eliminated significant amounts of amorphous organic material while preserving most of the pollen. Experiments with more than 3 sieving treatments showed that the additional sieving removed only marginal amounts of detrital material. However, the treated extract still contained a significant quantity of non-pollen material that needed removal prior to dating.

Pollen separation used a simple manually operated mouth pipetting system (Fig. 1). Components include a polystyrene mouthpiece, latex tubing (ca. $5 \mathrm{~mm}$ o.d., $3 \mathrm{~mm}$ i.d.), a disposable universal pipette tip, and a 9-inch borosilicate glass Pasteur pipette. The materials are very inexpensive and are readily available from any scientific equipment supplier. Tubing was cut to a comfortable work- 


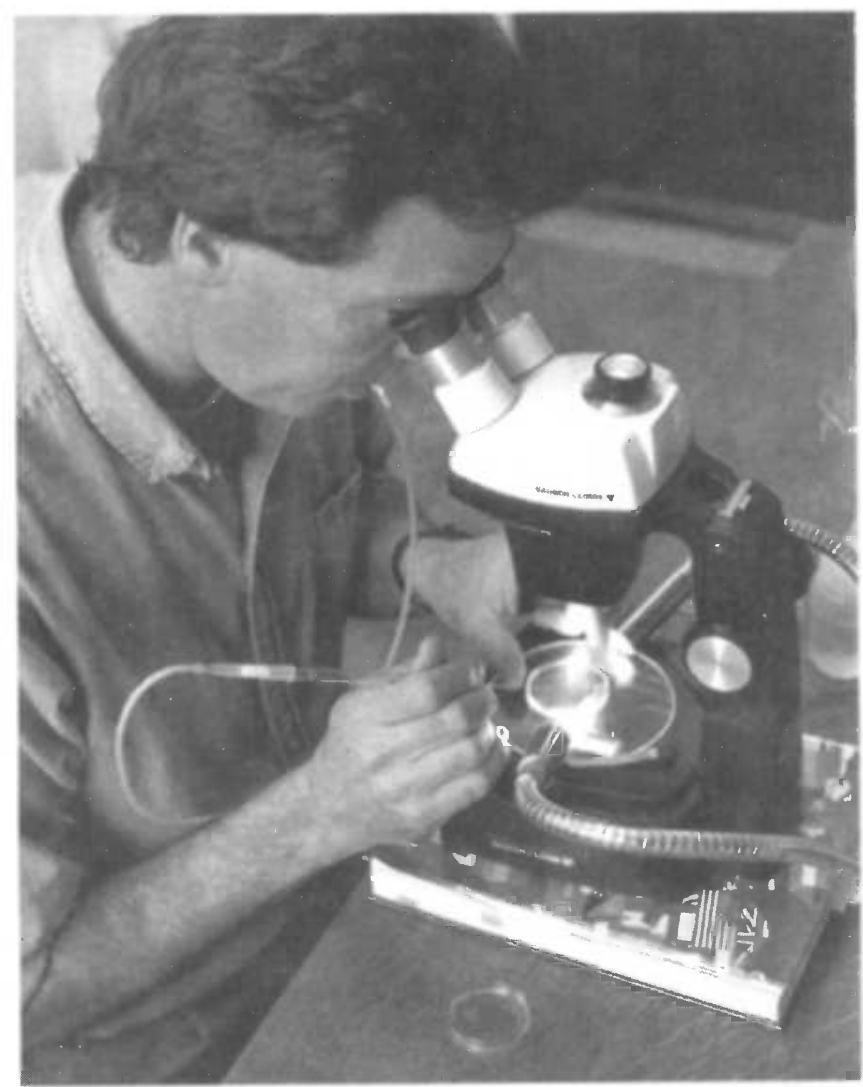

Figure 1 Photograph of the mouth pipetting apparatus in operation

ing length $(\mathrm{ca} .60 \mathrm{~cm}$ ) with one end fitted to the mouthpiece and the other end placed on the taper of the disposable pipette tip. A small swab of cotton was placed inside the disposable pipette tip to absorb moisture. The Pasteur pipette was prepared by heating over a flame and drawing out to an approximately $100-\mu \mathrm{m}$ orifice. This was then inserted into the large opening of the plastic disposable pipette.

A small (ca. $0.1 \mathrm{~mL}$ ) sample of pollen concentrate was ejected into a petri dish and flooded with deionized water to disperse the material. Pollen and other organic material quickly settled to the bottom. Pollen in the 38-74 $\mu \mathrm{m}$ fraction was easily identified for picking using a zoom binocular microscope in the range of 30-45× magnification under a fiber optic light source. The bleached pollen shows up clearly against a dark background. Pollen was aspirated into the Pasteur pipette. The small pipette orifice draws in the material through capillary action, and with gentle, periodic suction on the mouth pipette, one can rapidly vacuum pollen grains. This can be controlled to the extent that one can easily pick up a grain of pollen without also drawing in detritus that lies immediately adjacent. At this low magnification, we never found it difficult to hold the apparatus steady and guide the orifice to individual pollen grains. Generally 100-200 grains were collected in the pipette before ejecting the pollen directly into a vial for storage.

Samples were pipetted from the vials directly into quartz combustion tubes, and dried in a vacuum centrifuge. An excess of $\mathrm{CuO}$ oxidizer was added together with several $\mathrm{mg}$ of $\mathrm{Ag}$ powder, the tubes were flame-sealed under vacuum, and samples were combusted at $900{ }^{\circ} \mathrm{C}$. The resulting $\mathrm{CO}_{2}$ ali- 
quots (typically $25-70 \mu \mathrm{g}$ of carbon) were cryogenically purified and then converted to graphite by a hydrogen reduction with an Fe or Co catalyst, and ${ }^{14} \mathrm{C}$ was measured by AMS. Ultra-small samples such as these are sensitive not only to contamination of the samples by trace quantities of contemporary carbon (most likely adsorbed $\mathrm{CO}_{2}$ ), but also to contamination by "dead" carbon and/or to fractionation effects (Brown and Southon 1997; Kirner et al. 1997; van der Borg et al. 1997; Pearson et al. 1998). Numerous small aliquots of ${ }^{14} \mathrm{C}$-free coal and a Modern ${ }^{14} \mathrm{C}$ standard (HOxI) were used as process blanks to monitor the combustion and graphitization process, and results from these test samples were used to correct the measured pollen data (Donahue et al. 1990; Brown and Southon 1997). Dates were calculated according to Stuiver and Polach (1977).

\section{RESULTS AND DISCUSSION}

Brown et al. (1989) suggested that only 200-500 spruce pollen grains should be sufficient to obtain an AMS date. We found that due to the smaller size of pine pollen compared with spruce, and the difficulty in graphitizing very small samples, a sample of about 10,000 grains (ca. $70 \mu \mathrm{g}$ of carbon) was necessary for reliable AMS dating. Manual picking of pollen grains averaged 1000-2500 grains per hour depending on the sample material. Separating a 10,000-grain sample from Lake Moran required only $4 \mathrm{~h}$ labor, whereas the Santa Barbara Basin material averaged $8 \mathrm{~h}$ per sample because pollen was less abundant and chemically resistant organic material in the 38-74 $\mu \mathrm{m}$ fraction was more abundant. However, even for pollen-poor sites, isolation of a sufficient quantity of nearly pure pollen for AMS dating required only one day of additional labor after the chemical extraction procedures. For all samples, manual separation of pollen produced a nearly pure concentrate (Fig. 2).

The Lake Moran pollen sample from below the ash (LM 232-233) produced a date of $6880 \pm 175 \mathrm{BP}$ (Table 1). The LM 232-233 38-74 $\mu \mathrm{m}$ fraction received the same preparation treatment, except that pollen was not separated from the non-pollen matrix. This sample produced an identical date. The LM 232-233 >74 $\mu \mathrm{m}$ fraction, which contained no pollen but did include some charcoal, produced a date of $7000 \pm 60 \mathrm{BP}$, which is not inconsistent with the other 2 dates. The 38-74 $\mu \mathrm{m}$ and $>74 \mu \mathrm{m}$ fractions from above the ash (LM 228-229) give nearly identical dates, both younger than published Mazama Ash dates. However, pollen sample LM 228-229, from above the ash, returned a date of $7120 \pm 150 \mathrm{BP}$, our oldest Lake Moran date. Another pollen sample was picked from the same preparation and the date on this sample $(7040 \pm 80 \mathrm{BP})$ confirmed the earlier results.

Unlike the climactic Mazama Ash, the Tsoyawata Ash has few published dates and no AMS dates. Bulk sediment from below the ash at Osgood Swamp in California dated $6990 \pm 300$ BP (Haynes et al. 1967). Carbonized twig fragments from the upper $1 \mathrm{~cm}$ of a soil directly below the ash at a site near Crater Lake, Oregon, produced a date of $7015 \pm 45$ BP. At Wildcat Lake, Washington State, Blinman, Mehringer and Sheppard (1979) found both ashes and obtained a date of $6940 \pm 120 \mathrm{BP}$ on bulk sediment below the lower ash and a date of $6750 \pm 90$ BP on bulk sediment between the 2 ashes. They used a complex process derived from upper core pollen accumulation rates to calculate the time between the 2 ash falls to be approximately 140 yr. Other authors have suggested that a period of <200 yr separates the 2 ash falls (Bacon 1983; Young 1989).

Many efforts have been made to accurately date the climactic Mazama event (see Hallett et al. 1997 for a recent review). New AMS dates on charcoal and twig fragments from Mazama air-fall deposits suggest a weighted mean age of $6730 \pm 40 \mathrm{BP}$ (Hallett et al. 1997). Adding the estimated time between the 2 ashes to this date gives an approximate age of $6870-6930 \pm 40$ BP for the Tsoyawata event. Each of our pollen dates falls within this range of potential dates; however, the pollen dates from above the ash are older than the sedimentary matrix of the same strata. Previous studies have 

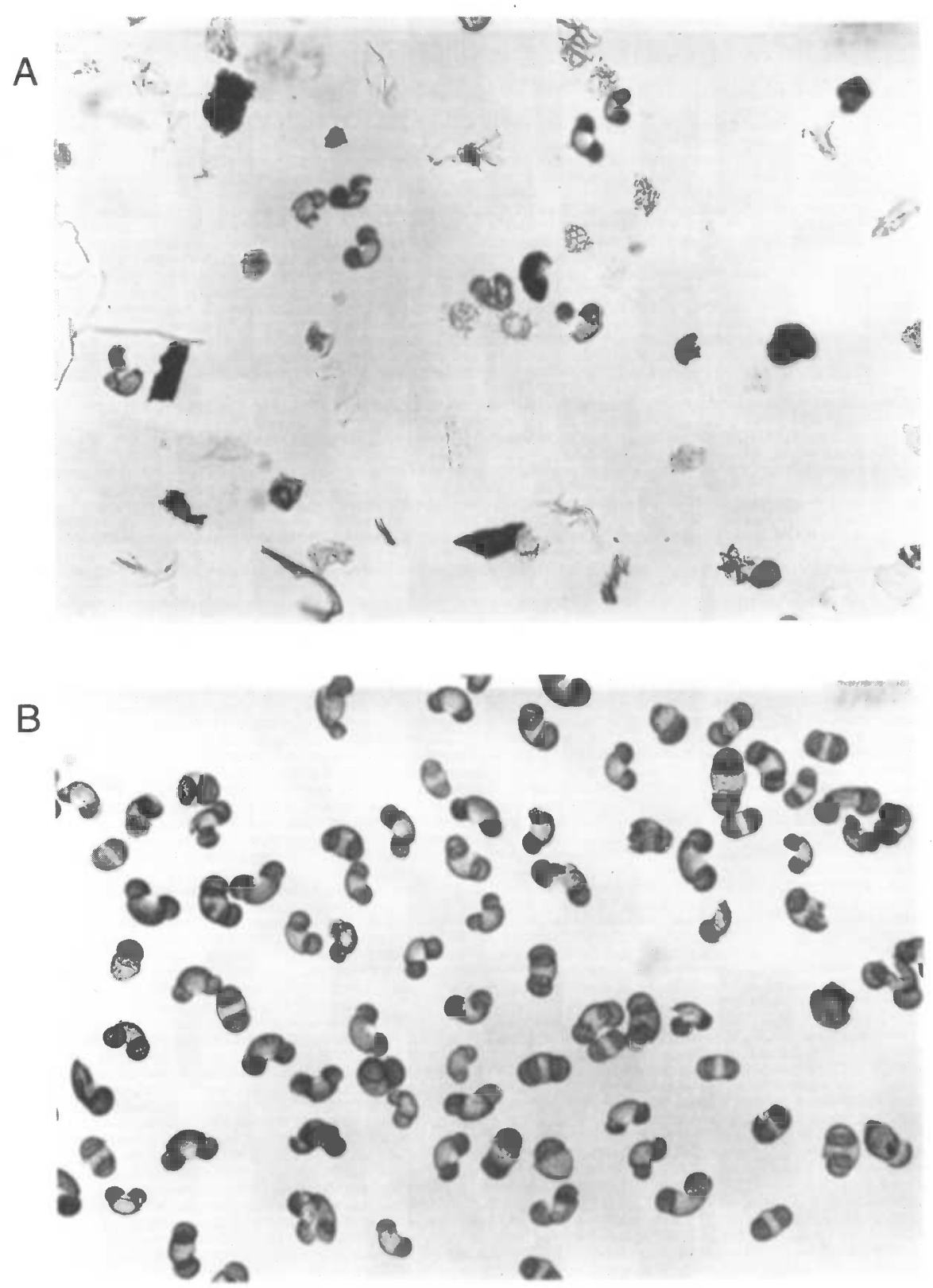

Figure 2 Photomicrographs showing samples before and after manual purification of the 38-74 $\mu \mathrm{m}$ fraction. 2A. Before separating pollen; note the presence of organic matter, unknown algal bodies and charcoal fragments. $2 \mathrm{~B}$. Pure concentrate remaining after separation of pine pollen.

consistently found pollen dates to be younger than the surrounding sediment, suggesting that the pollen represented a more accurate chronological indicator than the bulk sediment (Long et al. 1992; Regnell 1992). Although in general we would agree with this reasoning, our results suggest that the presence of reworked pollen in a sample could potentially provide a date older than sediment from the same strata. Mazama Ash may have altered soil infiltration rates, channeling runoff and leading 
to localized downcutting. Palynological evidence for this period shows high percentages of oak pollen, suggesting conditions drier than today, and possibly lowered lake levels. As lake levels fluctuate, pollen eroded from near-shore sediments can be redeposited in the central basin. This is more likely to occur at times of rapid climate change, precisely the periods for which paleoecologists desire accurate dates.

For the Santa Barbara Basin samples, the exact calendar age for each sample was known from varve counts (Tim Baumgartner, personal communication 1993). We dated pollen from strata prior to and associated with the ${ }^{14} \mathrm{C}$ spike caused by nuclear testing in the $1950 \mathrm{~s}$ and $1960 \mathrm{~s}$. The 3 pollen samples between 1963 and 1977 dated above modern as expected (Table 1), whereas the fraction modern averages $67 \%$ of the atmospheric value for this period, suggesting either that as much as $33 \%$ of the material is intrusive dead carbon, or that a large fraction of pre-bomb pollen is in the sample. Dates for the 4 pollen samples prior to the bomb peak were much older than expected, which suggests that any intrusive component must be quite old. We can suggest 2 possible reasons for these results; the pollen could be contaminated with residual old carbon, or a large contribution of old reworked pollen is in the sample. Similar arguments may also apply to charcoal in the Santa Barbara Basin since our 2 charcoal samples gave comparable or older dates than pollen. We are currently attempting to resolve this question, since it may have important implications for interpretation of pollen diagrams from the Santa Barbara Basin.

The $<38 \mu \mathrm{m}$ fractions produced very old dates. This is not simply due to the presence of marine organics, because the reservoir age for the Santa Barbara Basin is only $825 \mathrm{yr}$ (Ingram and Kennett 1995). These ages could be due to the presence of petroleum seeps or black carbon (Masiello and

Table 1 Dates obtained for samples from Lake Moran (LM) and the Santa Barbara Basin (SBB). All dates were determined at the Lawrence Livermore National Laboratory Center for Accelerator Mass Spectrometry (CAMS). Lake Moran samples are depth in $\mathrm{cm}$ down the core and Santa Barbara Basin samples represent calendar years AD.

\begin{tabular}{llclcc}
\hline CAMS \# & Location & Sample & Material & $\begin{array}{c}{ }^{14} \text { C age } \\
(\mathrm{BP})\end{array}$ & $\begin{array}{c}\text { Fraction } \\
\text { modern }\end{array}$ \\
\hline 42474 & LM & $228-229$ & Pollen & $7120 \pm 150$ & \\
46338 & LM & $228-229$ & Pollen & $7040 \pm 80$ & \\
29051 & LM & $228-229$ & $38-74 \mu$ m bulk fraction & $6620 \pm 60$ & \\
29052 & LM & $228-229$ & $>74 \mu$ m bulk fraction & $6650 \pm 50$ & \\
29053 & LM & $232-233$ & Pollen & $6880 \pm 170$ & \\
29054 & LM & $232-233$ & $38-74 \mu$ m bulk fraction & $6880 \pm 60$ & \\
29055 & LM & $232-233$ & $>74 \mu$ m bulk fraction & $7000 \pm 60$ & \\
26573 & SBB & $1963-1967$ & Pollen & $>$ Modern & 1.1998 \\
26574 & SBB & $1968-1972$ & Pollen & $>$ Modern & 1.1453 \\
26575 & SBB & $1973-1977$ & Pollen & $>$ Modern & 1.0725 \\
26580 & SBB & $1963-1967$ & $<38 \mu$ m bulk fraction & $4450 \pm 60$ & \\
26579 & SBB & $1968-1972$ & $<38 \mu$ m bulk fraction & $7400 \pm 60$ & \\
26578 & SBB & $1973-1977$ & $<38 \mu$ m bulk fraction & $4760 \pm 50$ & \\
39879 & SBB & $1860-1890$ & Pollen & $1080 \pm 140$ & \\
39880 & SBB & $1890-1920$ & Pollen & $1210 \pm 140$ & \\
39881 & SBB & $1920-1950$ & Pollen & $860 \pm 140$ & \\
39882 & SBB & $1933-1942$ & Pollen & $1760 \pm 240$ & \\
26577 & SBB & $1963-1967$ & Charcoal & $>$ Modern & 1.0793 \\
26576 & SBB & $1968-1972$ & Charcoal & $1060 \pm 100$ & \\
\hline
\end{tabular}


Druffel 1998). However, neither of these explanations seems reasonable for explaining the old pollen dates given the chemical treatment and appearance of the pollen.

\section{CONCLUSION}

We have developed a simple and inexpensive method for separating pure pollen samples for AMS ${ }^{14} \mathrm{C}$ dating. The equipment and method require virtually no investment. The only expensive equipment necessary, a binocular microscope capable of about $35 \times$ magnification, is commonly present in most pollen labs. We have demonstrated that samples sufficiently large for AMS dating (50-100 $\mu \mathrm{g})$ can be efficiently extracted even from pollen-poor sediments. We are continuing to test samples from the Santa Barbara Basin to better understand dating pollen from the marine environment. The pollen dates from Lake Moran are consistent with other published dates for the Tsoyawata/Mazama Ash; however, our results raise the possibility that pollen present in sediments above the ash may include some percentage of old pollen that has been reworked and redeposited. Our results suggest that bulk sediment dates for a particular stratum do not necessarily indicate when the pollen was deposited; direct dating of pollen provides a more accurate date.

\section{ACKNOWLEDGMENTS}

We thank Roger Byrne of the University of California, Berkeley, for assistance in developing our methodology and discussion of results, Tim Baumgartner of Scripps Institute for Oceanography for supplying sediment samples from the Santa Barbara Basin, and Eric Edlund for supplying sediment from Lake Moran. Michaele Kashgarian of the Center for Accelerator Mass Spectrometry, LLNL, provided assistance with the analysis, Lara Rozzell provided photomicrography and helped in pollen separation and Marie Allen and Jeremy Smith also assisted in pollen separation. Bob Karlin of the University of Nevada, Reno, provided laboratory facilities during the initial phase of the research. This research was supported by a grant from the Center for Accelerator Mass Spectrometry, Lawrence Livermore National Laboratory. This work was supported by the NOAA Paleoclimatology program (NA36GP0418) and by DOE (W-7405-Eng-48).

\section{REFERENCES}

Bacon CR. 1983. Eruptive history of Mount Mazama and Crater Lake Caldera, Cascade Range, USA. Journal of Volcanology and Geothermal Research 18:57-115.

Blinman E, Mehringer PJ Jr, Sheppard JC. 1979. Pollen influx and the deposition of Mazama and Glacier Peak tephra. In: Sheets PD, Grayson DK, editors. Volcanic activity and human ecology. New York: Academic Press. p 393-425.

Brown TA, Farwell GW, Grootes PM, Schmidt FH. 1992. Radiocarbon dating of pollen extracted from peat samples. Radiocarbon 34(3):550-6.

Brown TA, Nelson DE, Mathewes RW, Vogel JS, Southon JR. 1989. Radiocarbon dating of pollen by accelerator mass spectrometry. Quaternary Research 32: 205-12.

Brown TA, Southon JR. 1997. Corrections for contamination background in AMS ${ }^{14} \mathrm{C}$ measurements. $\mathrm{Nu}$ clear Instruments and Methods in Physics Research B 123:208-13.

Bruland KW. 1974. Pb-210 geochronology in the coastal environment. [PhD dissertation]. San Diego: Univer- sity of California.

Davis JO. 1978. Quaternary tephrochronology of the Lake Lahontan area, Nevada and California. Nevada Archeological Survey, Research Paper Number 7. Reno (NV): 137 p.

Davis OK. Pollen analysis of a Holocene late-glacial sediment core from Mono Lake, Mono County, CA. Quaternary Research. Forthcoming.

Donahue DJ, Linick TW, Jull AJT 1990 Isotope-ratio and background corrections for accelerator mass spectrometry radiocarbon measurements. Radiocarbon 32(2): $135-42$.

Emery KO. 1960. The sea off southern California, a modern habitat of petroleum. New York: John Wiley \& Sons. 366 p.

Faegri K, Iversen J. 1989. Textbook of pollen analysis. 4th ed. Chichester: John Wiley \& Sons. 328 p.

Hallet DJ, Hills LV, Clague JJ. 1997. New accelerator mass spectrometry radiocarbon ages for the Mazama tephra layer from Kootenay National Park, British Columbia, Canada. Canadian Journal of Earth Science 
34:1202-9.

Haynes CV Jr, Grey DC, Damon PE, Bennett R. 1967. Arizona radiocarbon dates VII. Radiocarbon 9:1-14

Hulsemann J, Emery KO. 1961. Stratification in recent sediments of Santa Barbara Basin as controlled by organisms and water character. Journal of Geology 69: 229-90.

Ingram BL, Kennet JP. 1995. Radiocarbon chronology and planktonic-benthic foraminiferal ${ }^{14} \mathrm{C}$ age differences in Santa Barbara Basin sediments, Hole 893A. In: Kennett JP, Baldwin JO, Lyle M, editors. Proceedings of the ocean drilling program scientific results 146: 19-27.

Kirner DL, Burky R, Taylor RE, Southon JR. 1997. Radiocarbon dating organic residues at the microgram level. Nuclear Instruments and Methods in Physics Research B123:214-7.

Koide MA, Soutar A, Goldberg ED. 1972. Marine geochronology with $\mathrm{Pb}-210$. Earth and Planetary Science Letters 14:442-6.

Krishnaswami S, Lal D, Amin BS, Soutar, A. 1973. Geochronological studies in Santa Barbara Basin. Limnology and Oceanography 18:763-70.

Long A, Davis OK, DeLanois J. 1992. Separation and ${ }^{14} \mathrm{C}$ dating of pure pollen from lake sediments: nanofossil AMS dating. Radiocarbon 34(3):557-60.

Masiello CA, Druffel ERM. 1998. Black carbon in deepsea sediments. Science 280:1911-3.

Mensing SA. 1993. The impact of European settlement on oak woodlands and fire: pollen and charcoal evidence from the Transverse Ranges, California. [PhD dissertation]. Berkeley: University of California. $216 \mathrm{p}$

Pearson A, McNichol AP, Schneider R J, Van Reden KF.
1998. Microscale AMS ${ }^{14} \mathrm{C}$ measurements at NOSAMS. Radiocarbon 40(1): 61-75.

Regnell J. 1992. Preparing pollen concentrates for AMS dating: a methodological study from a hard-water lake in southern Sweden. Boreas 21:373-7.

Regnell J, Everitt E. 1996. Preparative centrifugation: a new method for preparing concentrates suitable for radiocarbon dating by AMS. Vegetation History and $\mathrm{Ar}$ chaeobotany 5:201-5.

Richardson F, Hall, VA. 1994. Pollen concentrate from highly organic Holocene peat and lake deposits for AMS dating. Radiocarbon 36(3):407-12.

Schimmelmann A, Lange CB and Berger WH. 1990. Climatically controlled marker layers in Santa Barbara Basin sediments, and fine-scale core-to-core correlation. Limnology and Oceanography 35:165-73.

Soutar A, Crill PA. 1977. Sedimentation and climatic patterns in the Santa Barbara Basin during the 19th and 20th centuries. Geological Society of America Bulletin $88: 1161-72$

Stuiver M, Polach HA. 1977. Discussion: reporting of ${ }^{14} \mathrm{C}$ data. Radiocarbon 19(3):355-63.

van der Borg K, Alderliesten C, de Jong AFM, van den Brink A, de Hass AP, Kersemaekers HJH, Raaymakers, JEMJ. 1997. Precision and mass fractionation in ${ }^{14} \mathrm{C}$ analysis by AMS. Nuclear Instruments and Methods in Physics Research B123:97-101.

Young SR. 1989. Holocene eruptions at Mount Mazama, Oregon: characteristics and distribution of plinian airfall deposits. Continental Magmatism Abstracts. New Mexico Bureau of Mines and Mineral Resources, Bulletin 131. Socorro: $302 \mathrm{p}$ 